\title{
THE URINARY EXCRETION OF HISTAMINE IN CHILDREN
}

\author{
BY \\ H. M. ADAM and R. G. MITCHELL \\ From the Departments of Pharmacology and Child Life and Health, University of Edinburgh
}

(RECEIVED FOR PUBLICATION JULY 2, 1952)

The role of histamine in disease has long been a subject of speculation but until recently little was known about its metabolism because of difficulties in estimating the free, pharmacologically active form in body fluids (Gaddum, 1948, 1951). However, new methods for the separation and purification of histamine have made it possible to follow its excretion in the urine, where it occurs in free and conjugated forms (Anrep, Ayadi, Barsoum, Smith and Talaat, 1944; Roberts and Adam, 1950). Conjugated histamine, which is pharmacologically inactive, is mainly acetyl histamine (4( $\beta$-acetylaminoethyl)imidazole) and is formed by bacteria in the gut (Urbach, 1949).

In adults the excretion of free histamine changes little from day to day but that of the conjugate varies between wide limits. When histamine is given by slow intravenous infusion, about $1 \%$ of the dose appears in the urine as free histamine and there is no detectable increase in the urinary conjugate. After oral administration, however, it appears in the urine mostly in the conjugated form (Adam, 1950). These facts suggest that the normal excretion of free histamine in the urine may represent the continuous formation or liberation of histamine in the tissues and that the excretion of the conjugate is related to the amount of free histamine in the alimentary tract.

Little is known about the metabolism of histamine in childhood, and the object of the present investigation was to determine whether infants and children excrete histamine and, if so, the form and quantity in which it occurs. At the same time we investigated the urinary excretion of histamine in infantile gastroenteritis, since it has been suggested that the absorption of histamine from the intestine causes symptoms in this condition (Mellanby, 1916).

\section{Selection of Children for the Investigation}

Since reliable 24-hour specimens of urine can only be obtained from children under close supervision by trained nursing staff, the specimens of urine were collected from children in the wards and convalescent homes of the Royal Hospital for Sick Children, Edinburgh. Strictly speaking, therefore, the children were convalescent; the majority had recovered from minor respiratory infections; a few had been admitted for investigation of vague symptoms for which no cause had been found; others had healed fractures and were being kept in hospital for remedial exercises. Some of the infants had been in hospital with gastro-enteritis, but all had fully recovered and were ready to go home.

All the children were on normal diets and none was receiving drugs. Children with a history or family history of allergic diseases, and unduly fat or thin children, were not selected. The subjects of this investigation, therefore, can reasonably be considered as healthy children.

Urine from infants with gastro-enteritis was collected at the gastro-enteritis unit of the City Hospital for Infectious Diseases, Edinburgh. The first specimen was collected as soon as possible after admission from male infants with symptoms and signs of severe gastro-enteritis; that is to say, every infant was passing frequent, loose, green stools and showed signs of dehydration. The disease was of the endemic type, since no epidemic occurred during the period of the investigation. While the urine was being collected the infants were given Hartmann's solution, by mouth or by intravenous drip, and either sulphadiazine or chloramphenicol by mouth. In each case the second collection was made one week after the first. By this time all the infants were on milk feeds and were passing normal stools.

\section{Pharmacological Methods}

Extraction of Histamine. The method used was that of Roberts and Adam (1950), whose paper should be consulted for full details.

Free Histamine. Free histamine is separated from conjugated histamine and other substances in $50 \mathrm{ml}$. of urine by adsorption on a column of the cationic exchanger 


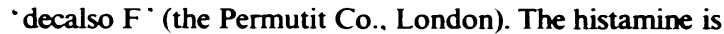
then eluted by treating the column with concentrated ammonium hydroxide followed by chloroform saturated with ammonia gas. After evaporation of the eluent under reduced pressure the residue is taken up in $10 \mathrm{ml}$. of $0.9 \% \mathrm{NaCl}$ and neutralized; in this way the histamine is concentrated fivefold. By this method, the mean recovery when histamine is added to various body fluids in the range of 0.5 to $5 \mu \mathrm{g}$ is $67 \%=1 \cdot 1$. This fraction is a characteristic of the decalso column and a correction can be applied to the results; in the present paper, the results are uncorrected.

Conugated Histamine. Urinary percolate, $10 \mathrm{ml}$., from the decalso column is applied to a column made of charcoal and sand. The charcoal adsorbs the conjugated histamine along with other substances and acid alcohol is used as the eluent. The purification thus achieved is only partial. The eluent is evaporated to dryness and the residue boiled in concentrated $\mathrm{HCl}$ to hydrolyse the conjugate. After evaporation of the acid the residue is taken up in $0.9 \% \mathrm{NaCl}$, neutralized, and made up to $10 \mathrm{ml}$. The mean recovery when $2.5 \mu \mathrm{g}$ of acetyl histamine is added to $5 \mathrm{ml}$. of urine is $82 \%=2 \cdot 4$.

Estimation and Identification of Histamine. The histamine values are all calculated in terms of the base on the assumption that this represents $36 \cdot 16 \%$ of the weight of the phosphate. The extracts were tested on a strip of guinea-pig ileum suspended in $2 \mathrm{ml}$. of Tyrode's solution containing atropine (0.1 $\mu \mathrm{g}$ per $\mathrm{ml}$.) and were compared with a standard solution of histamine acid phosphate (British Drug Houses, Ltd.). Mepyramine maleate (May and Baker, Ltd.) in a concentration of $2 \times 10^{-8}$ was added to the bath at the end of the assay.

\section{Clinical Methods}

Owing to the difficulty of obtaining reliable 24-hour specimens of urine from females, all the children selected were males. The urine was collected in chemically clean bottles of $600 \mathrm{ml}$. capacity, each of which contained $3 \mathrm{ml}$. of $2 \mathrm{~N} \mathrm{HCl}$ to ensure that the specimen was kept at less than $p \mathrm{H} \mathrm{4}$. After collecting into one bottle for 12 hours this bottle was stored at $0^{-} \mathrm{C}$., and the collection continued for a further 12 hours in a second bottle. Samples for bacteriological examination were taken from each bottle before pooling the whole 24-hour specimen. The extraction of histamine was started in every case within six hours of completing the collection.

In the older children the urine was passed directly into the bottle by means of a funnel fixed in the neck. Infants were placed on a metabolic bed and the urine passed down through tubing into a bottle below the bed. Various types of collecting apparatus were tried at first but were all discarded in favour of Paul's colostomy tubing of 1 in. width, which was strapped with adhesive strapping to the infant's penis. This tubing is very light and no trouble from kinking or backflow was encountered owing to its wide lumen and easily distended wall. Since the collections lasted for only 24 hours, the disadvantages of the prolonged use of strapping did not arise. The tubing was washed thoroughly before use as the powdered chalk in new tubing was found to adsorb histamine.

\section{Results}

The healthy children were divided into four groups according to their body weight at the time of collection. These groups correspond roughly to the following age groups: 1 year and under, 2 to 5 years, 6 to 9 years, and 10 to 12 years. The results are presented in Table 1, and those for the free histamine are also shown graphically in Fig. 1. The results obtained in the infants with gastro-enteritis are contained in Table 2. The first five of these infants received chloramphenicol during the acute stage of the illness; the next four, sulphadiazine; and the last infant, no drug treatment.

When the histamine equivalent for the conjugate in extracts of infants ${ }^{\circ}$ urine was less than $0.01 \mu \mathrm{g} / \mathrm{ml}$., the amount of conjugate is shown as less than the value calculated from the threshold dose of the standard solution of histamine. These values therefore varied with the sensitivity of the strips of ileum in the assays. In our calculations we have assumed that no histamine was present in these samples.

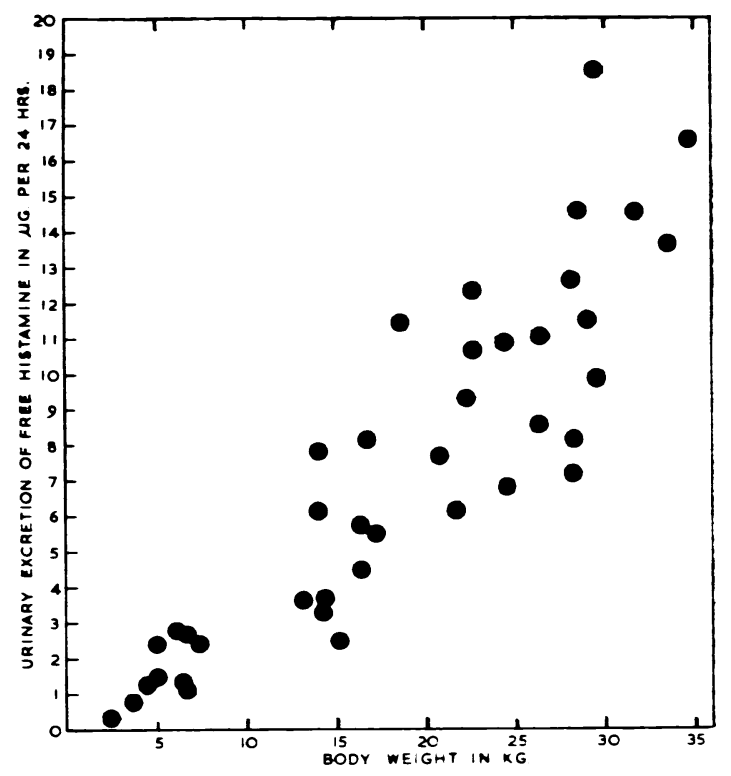

FIG. 1.-Results for free histamine in healthy children.

We have also expressed the 24-hourly excretion of histamine in $\mu \mathrm{g}$. per $\mathrm{kg}$. of body weight but only the mean values and the range are given in the table.

Fig. 2 shows the inhibitory effect of mepyramine maleate on equiactive doses of the standard solution of histamine and of an extract of infant's urine from the decalso column. The fact that the rate of recovery 
TABLE 1

EXCRETION OF HISTAMINE IN FOUR GROUPS OF HEALTHY INFANTS



for the extract is the same as that for the standard strengthens the evidence that the activity of the extract is due to histamine. A further test consisted in boiling an extract from the decalso column for one hour in concentrated $\mathrm{HCl}$ and comparing its activity with that of an unboiled extract of the same urine. The histamine equivalents of these extracts agreed to within $10 \%$.

TABLE 2

URINARY EXCRETION OF HISTAMINE IN ACUTE AND CONVALESCENT STAGES OF INFANTILE GASTROENTERITIS

\begin{tabular}{|c|c|c|c|c|}
\hline \multirow[t]{2}{*}{ Infant } & \multicolumn{2}{|c|}{$\begin{array}{l}\text { Free Histamine } \\
\text { ( } \mu_{8} \text { per } 24 \text { hrs.) }\end{array}$} & \multicolumn{2}{|c|}{$\begin{array}{c}\text { Conjugated Histamine } \\
\text { ( } \mu_{\mathrm{g}} \text {. per } 24 \text { hrs.) }\end{array}$} \\
\hline & Acute & Convalescent & Acute & Convalescent \\
\hline $\begin{array}{l}\text { W.H. } \\
\text { E.L. } \\
\text { P.O'K. } \\
\text { A.R. } \\
\text { J.R. } \\
\text { D.W. } \\
\text { S.H. } \\
\text { J.G. } \\
\text { N.R. } \\
\text { B.S. }\end{array}$ & $\begin{array}{l}1 \cdot 0 \\
0 \cdot 5 \\
2 \cdot 8 \\
0 \cdot 7 \\
0 \cdot 5 \\
1 \cdot 0 \\
1 \cdot 0 \\
0 \cdot 6 \\
1 \cdot 2 \\
1 \cdot 6\end{array}$ & $\begin{array}{l}2 \cdot 4 \\
1 \cdot 2 \\
3 \cdot 2 \\
0 \cdot 7 \\
1 \cdot 2 \\
0 \cdot 6 \\
2 \cdot 2 \\
0 \cdot 6 \\
0 \cdot 9 \\
3 \cdot 3\end{array}$ & $\begin{array}{r}<2 \\
3 \\
<6 \\
<3 \\
1 \\
<5 \\
3 \\
2 \\
18 \\
9\end{array}$ & $\begin{array}{r}<10 \\
<4 \\
<8 \\
9 \\
2 \\
<5 \\
5 \\
3 \\
<5 \\
<3\end{array}$ \\
\hline Mean ... & $1 \cdot 1$ & $1 \cdot 6$ & $3 \cdot 6$ & $1 \cdot 9$ \\
\hline
\end{tabular}

- Calculated as histamine.
The specimens were collected under clean but not sterile conditions, and therefore samples of urine

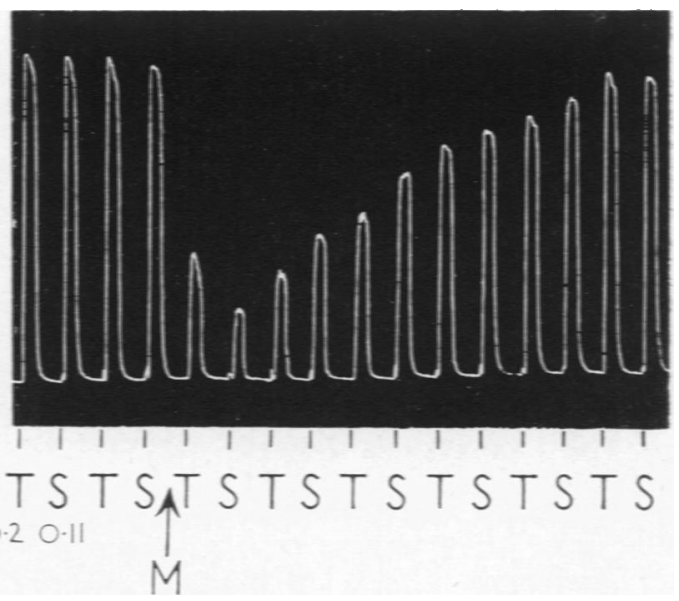

Fig. 2.-Responses of guinea-pig ileum to equiactive doses of urine extract $(T)$ and histamine standard $(\mathrm{S}, 0-1 \mu \mathrm{g} / \mathrm{ml}$.). Test solution was $50 \mathrm{ml}$. infant's urine extracted on a decalso column and concentrated fivefold.

Arrow represents addition of $0.2 \mathrm{ml}$. mepyramine makate (concentration $2 \times 10^{-5}$ ). Time interval between doses, 90 secs. 
taken just before extraction were cultured. No growth occurred in the majority of cases but six showed a few colonies of bacteria and five showed a moderate growth of Bact. coli. In no case was the urine infected before collection and there was no evidence that the bacteria cultured had any effect on the values obtained for free or conjugated histamine.

\section{Discussion}

Infants and young children excrete free and conjugated histamine in the urine. It is evident that as the body weight increases so does the 24-hourly excretion of free histamine. This relationship is less definite for the conjugate, the values for which are more widely scattered. As the average weight rose from $5 \cdot 4 \mathrm{~kg}$. to $30 \cdot 1 \mathrm{~kg}$. the amount of free histamine rose from 1.7 to $12.7 \mathrm{\mu g}$. per 24 hours. When the excretion was calculated as $\mu \mathrm{g}$. $/ \mathrm{kg}$. $/ 24$ hours the mean for the two heavier groups $(0.42 \pm 0.026) *$ was significantly $(\mathrm{P}<0.05)$ higher than the mean for the two lighter groups $(0 \cdot 315 \pm 0 \cdot 023)$. Nevertheless the results are thought to justify the use of this method of calculation and to show that it is more likely to give more consistent results than any other simple method. This conclusion is supported by calculations based on the results of Roberts and Adam (1950) who found that the average 24-hourly excretion of free histamine by five healthy adult males was $21.6 \mathrm{~kg}$. These authors did not record body weights but if we assume that the mean body weight of these men was $70 \mathrm{~kg}$., their excretion of free histamine was $0.31 \mu \mathrm{g}$. $/ \mathrm{kg}$. This suggests that the excretion of free histamine is directly proportional to the body weight not only during growth but also after it has stopped.

Infants excrete only minute quantities of the conjugate: this is consistent with the excretion that might be expected with a milk diet. Anrep et al. (1944) found in the rat and dog that diets of milk and casein had no effect on the excretion of conjugated histamine, whereas meat or histamine given by mouth greatly increased it. Again, it is possible that the bacterial flora in the alimentary tract of infants is poor in organisms that acetylate histamine.

The fact that in all the children the excretion of free histamine is less variable than that of the conjugate lends additional support to the view that the free histamine derives mainly from the tissues and the conjugate from the alimentary tract. On this view, the normal excretion of free histamine is likely to have some physiological meaning but that of the conjugate is not.

\footnotetext{
- Standard error of the mean
}

\section{Histamine in Gastro-enteritis}

The theory that the symptoms of gastro-enteritis in infants are caused by the absorption of toxic bacterial products formed in the gut has been advanced repeatedly (Jeans and Marriott, 1947; Ivy, 1948; Kerpel-Fronius, 1948). Mellanby (1916) was the first to suggest that histamine might be one of these products, since it was known that the alimentary tract contained bacteria which could decarboxylate histidine in culture. Many organisms which decarboxylate histidine in this way have since been identified in the faeces of healthy adults, but there is no evidence that they occur in significant numbers in the intestinal contents of infants with gastro-enteritis (Gale, 1940, 1944).

Histamine is normally present in the faeces in the free and conjugated forms (Myhrman and Tomenius, 1939; Urbach, 1949): some of the free histamine is probably destroyed by histaminase in the intestinal mucosa and some of the conjugate is absorbed but produces no symptoms because it is inert. If, on Mellanby's view, histamine causes toxic effects after it is absorbed, we must assume that appreciable quantities of free histamine reach the circulation unchanged, either because unusually large amounts are formed in the intestine, or because it is no longer conjugated or destroyed. In the dog various agents, such as chloroform and alcohol, promote the absorption of histamine after they have been applied directly to the mucosa of the gut (Mammoser and Boyd, 1929). They may act either by dissolving histamine or by interfering with its inactivation or in other ways. It is conceivable, on this analogy, that inflamed gut, as compared with healthy gut, allows histamine to pass more freely into the circulation. When histamine is given by slow, intravenous infusion it is more easily detected in the urine than in the blood, probably because it is concentrated in the kidneys (Adam, 1950). Hence the passage of free histamine from the gut into the general circulation in amounts large enough to produce the symptoms of gastro-enteritis would be expected to increase the amount excreted in the urine. In the present investigation the difference between the amount of free histamine excreted in the acute stage of gastro-enteritis and the amount excreted by the same child after recovery was not significant. The results, therefore, do not support the view that the absorption of histamine from the alimentary tract is a cause of symptoms in infantile gastro-enteritis.

\section{Summary}

The urinary excretion of histamine has been investigated in $\mathbf{4 0}$ healthy children. 
Children excrete histamine in free and conjugated forms. The rate of excretion of free histamine was approximately proportional to the body weight and varied from 0.30 to $0.42 \mu \mathrm{g} . / \mathrm{kg}$. $/ 24$ hours.

The urinary excretion of histamine was also investigated in 10 infants with gastro-enteritis in the acute stage and during convalescence. The difference between the mean values at each stage was not significant.

We wish to thank the consulting staff of the Royal Hospital for Sick Children and Dr. A. Joe, Medical Superintendent of the City Hospital, for permission to investigate patients in their wards andalso the nursing staff at these hospitals without whose willing cooperation this work could not have been carried out. We are grateful to Professor J. H. Gaddum, F.R.S., for criticism, and to Mr. R. P. Stephenson, of the Pharmacology Depart- ment, for generous help with the construction of an apparatus for the assays.

\section{Refenences}

Adam, H. M. (1950). Owart. J. Exp. Physiol., 35, 281

Anrep, G. V. Ayedi, M. S., Barsoum, G. S. Smith, J. R. and Talant, M. M. (1944). J. Physiol., Lond, 103, 155.

Gaddum, J. H. (1948). Brit. med. J., 1, 867.

(1951). Bbid., $2,987$.

Gale, E F. (1940). Biochem. J., 34, 392

- (1944). Brit. med. J., 1, 631 .

Ivy, A. C. (1948). In Brennemann's Practice of Pediatrics, vol. 1, ch. 20. W. F. Prior Co. Inc. Hagerstown, Maryland.

Jeans, P. C. and Marriot, W. McK. (1947). Infout Nutrition, th ed. Henry Kimpton, London.

Kerpet-Fronius, E (1948). Acta paediat., Uppsala, 36, 611.

Mammoser, L F. and Boyd, T. E. (1929). Proc. Soc. exp. Biol, N.Y., 26,765

Mellanby, E. (1916). Qwart. J. Med. 9, 165

Myhrman, G. and Tomenius, J. (1939). Arch. exp. Path. Phamak., 193, 14.

Roberts, M. and Adam, H. M. (1950). Brit. J. Pharmacol., 5, 526. Urbach, K. F. (1949). Proc. Soc. exp. Biol., N.Y., 70, 146. 